\title{
AVALIAÇÃo DA COMPOSIÇÃo CENTESIMAL, AMINOÁCIDOS E MERCÚRIO CONTAMINANTE DE SURIMI ${ }^{1}$
}

\author{
Nádia Valéria Mussi de MIRA, Ursula Maria LANFER-MARQUEZ ${ }^{2, *}$
}

\begin{abstract}
RESUMO
A produção de surimi no Brasil ainda constitui atividade pouco explorada, mas com grande potencial de crescimento, seguindo tendências internacionais. O surimi representa uma nova fonte e uma alternativa promissora na elaboração de produtos alimentícios de alto valor nutricional (hambúrgueres, salsichas, análogos de peixe), e de hidrolisados protéicos. Foi objetivo caracterizar um tipo de surimi, produzido a partir de peixes marinhos, visando contribuir para o estabelecimento de padrões de identidade e qualidade deste produto. O surimi foi estudado durante um ano em termos de composição centesimal, perfil de aminoácidos e níveis de mercúrio. O teor de umidade da amostra oscilou entre 79,5 e 88,7\%, decorrente da eficiência do processo de centrifugação e da sazonalidade das espécies de peixe. Os teores protéicos variaram ao longo do ano entre 83,5 a $90,7 \%$ em b.s., os teores lipídicos foram reduzidos e os de carboidratos, insignificantes. Os valores calóricos variaram entre 43 e $73 \mathrm{kcal} / 100 \mathrm{~g}$, com um valor médio de $58 \mathrm{kcal} / 100$ g no produto integral. O perfil de aminoácidos manteve-se praticamente constante, a composição foi balanceada, rica em aminoácidos essenciais, atendendo aos requerimentos nutricionais. Os teores de mercúrio total foram inferiores ao limite de $0,5 \mathrm{mg} / \mathrm{kg}$ estabelecido pela legislação brasileira para "produtos da pesca".

Palavras-chave: surimi, composição química, perfil de aminoácidos, mercúrio.
\end{abstract}

\section{SUMMARY}

CHEMICAL COMPOSITION, AMINO ACIDs AND CONTAMINATION BY MERCURY OF SURIMI. In Brazil, the production of surimi has not been fully explored though a significant increase in development of technology and marketing is expected, following international tendencies. Surimi represents a new source and a promising alternative for the development of food products with a high nutritional value (hamburgers, sausages, fish analogs), as well as the production of protein hydrolysates. The purpose of this study was to characterize surimi manufactured with two species of marine fishes and to contribute with the establishment of identity and quality standards. This product was analysed over one year in terms of chemical composition, calories, amino acid profiles and mercury levels. Moisture contents ranged from $79.5 \%$ to $88.7 \%$, and seemed to be affected by compression force and also by the seasonal variation of fish species. Protein contents oscillated between 83.5 and $90.7 \%$, on dry basis, fat contents were low and carbohydrate contents were negligible. Energy values ranged between 43 and $73 \mathrm{kcal} / 100 \mathrm{~g}$ with a mean value of $58 \mathrm{kcal} / 100 \mathrm{~g}$ wet product. The amino acid composition is well balanced and attends nutritional requirements. Total mercury concentrations were below the maximum level of $0.5 \mathrm{mgHg} / \mathrm{kg}$ determined by Brazilian laws. Keywords: surimi; chemical composition; seasonal variation; amino acid, mercury.

\section{1 - INTRODUÇÃO}

No Brasil, a ampla costa litorânea, incluindo regiões de climas tropicais e subtropicais, estimula a pesca comercial, fato que se torna relevante considerando que o pescado desempenha importante papel na nutrição, pelo conteúdo em proteínas, vitaminas e minerais. Nas regiões Norte, Nordeste e Noroeste ainda predomina a pesca artesanal, enquanto no Sul e Sudoeste, mais da metade da produção pesqueira é representada pela pesca industrial (IBAMA/IBGE [15])

Com as operações de pesca comercial, são também capturadas diversas espécies de pequenos peixes, na maioria das vezes, desprezados posteriormente. Entre essas espécies encontram-se peixes pelágicos e demersais, alguns peixes pouco comuns e todos de valor comercial muito reduzido, devido à grande heterogeneidade na composição, tamanho, textura, aparência e sabor, o que impossibilita a comercialização individual por espécie. Mundialmente, cerca de 27 milhões de toneladas/ano ( $25 \%$ da produção) de espécies marinhas são descartadas como "lixo" proveniente da pesca intensiva (RUSTAD [35], VASCONCELLOS \& GASALLA [42]). O aproveitamento desse pescado demanda infraestrutura e marketing para tornar-se rentável (RUSTAD [35]).

${ }^{1}$ Recebido para publicação em 06/06/2004. Aceito para publicação em 03/10/2005 (001359).

${ }^{2}$ Universidade de São Paulo. Depto. Alimentos e Nutrição Experimental

Faculdade de Ciências Farmacêuticas. Av. Lineu Prestes, 580 bloco 14

São Paulo/SP. 05508-900.

*A quem a correspondência deve ser enviada.
A utilização de espécies de peixes com baixa expressão econômica vem sendo tema de pesquisa em certas regiões do Brasil. Na Amazônia, peixes de baixo valor comercial têm sido utilizados como matéria-prima na produção de minced fish, o que pode representar uma opção tecnológica viável para a região (TENUTA-FILHO \& JESUS [40], JESUS et al. [17]). Portanto, uma opção de uso destas espécies de reduzido valor comercial é o seu emprego como matériaprima na obtenção de "minced fish" e/ou de surimi.

Surimi pode ser definido como um concentrado de proteínas miofibrilares, produzido por repetidas lavagens do pescado triturado, constituindo uma pasta que pode ser congelada após a adição de crioprotetores para a manutenção das características de gelificação, importantes na elaboração de produtos derivados (ARECHE [3], LEE [23], SUZUKI [39], JOHNSTON [18], PARK \& MORRISSEY [32]) Os peixes magros e com músculo claro são melhores para a produção de surimi, uma vez que os peixes considerados gordos, como, por exemplo, cavala (Scomberomus cavala) e jurel (Scomber japonicus) apresentam maior tendência de oxidação lipídica e a coloração escura resulta em menor aceitação pelo consumidor.

Assim, o surimi deve ser entendido como um produto intermediário na fabricação de novos produtos alimentícios, como empanados de peixe, hambúrgueres, salsichas e produtos que imitam análogos de pescado, (camarão, patas de caranguejo, carne de siri, molusco). O aroma e o sabor proporcionados pela incorporação do surimi em análogos de pescado se assemelham ao produto original e o "National Fisheries Institute" dos E.U.A. permitiu a reti- 
rada da palavra "imitação" das embalagens de produtos à base de surimi (PARK \& MORRISSEY [32]). O surimi vem sendo empregado também para produção de concentrados e hidrolisados protéicos de peixe, com potencial de utilização como suplemento em alimentos à base de cereais ou em sopas, substituindo uma variedade de proteínas animais e vegetais (HALL \& AHMAD [13], LEE [24, 25], VENUGOPAL $\&$ SHAHIDI [43]).

No Japão, devido à grande disponibilidade da espécie Alaska pollack (Theragra chalcogramma), o surimi é produzido basicamente a partir deste peixe, tendo-se verificado um aumento no seu consumo de 58.200 toneladas métricas em 1988 para 163.200 em 1992. Este fenômeno foi resultado de uma operação de marketing internacional, fazendo com que a tecnologia de produção do surimi passasse a ser de interesse da comunidade científica global (LEE [25]).

Os Estados Unidos ocupam a quarta posição em volume de pesca no mundo, atrás da China, Japão e Índia (CARLBERG \& OLST [7]) e são os maiores produtores de surimi. Em 2004, os Estados Unidos exportaram 200.965 toneladas de surimi, com destino para o Japão e Canadá (Fishery Statistics Division [41]). O Japão é o principal importador, devido ao elevado consumo de produtos típicos derivados do surimi, como kamaboko (cozido a vapor), tempura (frito) e chikuwa (assado), ocupando $75 \%$ da fatia do mercado mundial (ISHIKAWA [16], LEE [24]).

Segundo estatísticas comerciais o volume das exportações dos 25 países membros da União Européia subiu 23\% em 2004 com relação ao ano anterior, sendo os principais produtos os filetes de Alaska pollack, merluza congelada e surimi (INFOPESCA [9]).

Embora o surimi tenha sido originado no Japão, nos últimos 25 anos um "novo" surimi vem sendo produzido para atender às preferências alimentares da população do Sudeste da Ásia, Coréia, China, Chile, Argentina, França, Espanha e América do Norte O comércio globalizado propiciou a aceitação e a preferência pelo consumidor de um surimi obtido de diferentes espécies de peixes e de práticas econômico-culturais distintas, tendo criado uma cadeia de commodity (MANSFIELD [27]).

A produção de surimi no Brasil é incipiente, restrita a algumas localidades e de distribuição limitada. Correspondentemente, não foram encontrados na literatura estudos locais sobre o produto em pauta, que o caracteriza sob aspectos nutricionais e tecnológicos importantes.

Visando contribuir para o estabelecimento de padrões de identidade e de qualidade do surimi, o objetivo deste trabalho foi o de analisar o produto durante 12 meses em relação à composição centesimal e perfil de aminoácidos, além de verificar contaminação relativa ao mercúrio. Assim, os resultados deste trabalho, apesar de se referirem exclusivamente ao surimi produzido por uma única empresa, poderão ser úteis para dar início ao estabelecimento de parâmetros que definem a sua qualidade.

\section{2 - MATERIAL E MÉTODOS}

\section{1 - Obtenção do surimi}

Amostras de $2 \mathrm{Kg}$ de surimi, sem a adição de crioprotetores, foram cedidas mensalmente, durante o período de um ano pela empresa Takaki Cia Ltda, localizada em Suzano, Estado de São Paulo. De acordo com informações da empresa, são empregadas duas espécies de peixes de água salgada "Maria-Luíza" (Paralonchurus brasiliensis) e "Perna-de-moça" (Cynoscion virescens), ambos de baixo valor comercial, em proporções variáveis de acordo com a demanda, mas sempre com predominância do "Maria Luiza". O processo de fabricação industrial do surimi inclui decapitação, evisceração, lavagem com água potável e separação mecânica de músculos, pele e ossos, em equipamento sem marca, com orifícios de $4 \mathrm{~mm}$ de diâmetro, obtendo-se assim o minced fish. O rendimento do processo até essa etapa é em média de $50 \%$ a partir do peixe descabeçado e eviscerado.

O "minced fish" assim obtido foi submetido a três ciclos de lavagem com água ao redor de $8^{\circ} \mathrm{C}$ e tempo de contato de 10 minutos, na proporção de $250 \mathrm{~L}$ de água para $15 \mathrm{~kg}$. O produto foi centrifugado para remoção da água ( $15 \mathrm{~kg} / 4 \mathrm{~min}, 3500 \mathrm{rpm}$ ), passado em peneira com malha de $1 \mathrm{~mm}$ de diâmetro, congelado e transportado para o laboratório.

\section{2 - Preparo da amostra}

Para as análises químicas, as amostras de surimi foram descongeladas e homogeneizadas em homogeneizador Omni H-115, sendo parte utilizada para análise de umidade, lipídios, proteínas e resíduo mineral, enquanto a outra parte foi submetida à liofilização, seguida de homogeneização, acondicionamento em frascos de vidro e armazenamento em congelador até o momento das demais análises químicas.

\section{3 - Composição centesimal e valor calórico}

A umidade foi determinada pela perda de voláteis a $105^{\circ} \mathrm{C}$, o nitrogênio total, pelo método de micro-Kjeldahl, usando o fator de 6,25 para conversão em proteína, e as cinzas, por incineração em chapa elétrica e combustão a $550^{\circ} \mathrm{C}$, segundo a AOAC [2]. A fração lipídica foi determinada pelo método de FOLCH et al. [12]. Todas as análises foram realizadas em triplicata. O valor calórico foi calculado como [(proteína x 4 kcal/g) + (lipídeos x 9 kcal/g) + (carboidratos x $4 \mathrm{kcal} / \mathrm{g}$ )].

\section{4 - Composição em aminoácidos}

A análise de aminoácidos foi realizada após hidrólise ácida das amostras liofilizadas, com $\mathrm{HCl}$ a $6 \mathrm{~N}$, durante 22 horas, a $110^{\circ} \mathrm{C}$, em ampolas de vidro seladas a vácuo. As ampolas foram abertas e mantidas em dessecador contendo pastilhas de $\mathrm{NaOH}$, para remover o $\mathrm{HCl}$. As amostras 
foram ressuspensas em tampão citrato (Na-S, Beckman Instr., Palo Alto, CA), diluídas convenientemente e filtradas em membrana Millipore de 0,22 $\mu \mathrm{m}$ (SPACKMAN [37]). A metionina e a cisteína foram analisadas após oxidação prévia com ácido perfórmico (MOORE [29]). O triptofano não foi quantificado.

Os aminoácidos foram separados por cromatografia de troca iônica, em autoanalisador Beckman, modelo 7300, e quantificados por reação com ninidrina pós-coluna. $\mathrm{O}$ equipamento foi operado em condições para hidrolisados protéicos de acordo com as normas do fabricante, utilizando-se coluna de $20 \mathrm{~cm}$ de comprimento, contendo resina de troca iônica de sódio.

\section{5 - Análise do teor de mercúrio}

Os níveis de mercúrio contaminante foram quantificados em 7 amostras liofilizadas, por espectrofotometria de absorção atômica, de acordo com CHICOUREL et al. [8].

\section{6 - Análise estatística}

A análise de variância (ANOVA) foi utilizada para identificar diferenças significativas $(\mathrm{p}<0,05)$ nos teores de cada um dos aminoácidos durante o período de 12 meses de acordo com metodologia descrita por NETER et al. [31].

\section{3 - RESULTADOS E DISCUSSÃO}

\section{1 - Composição centesimal e valor calórico}

Na Tabela 1 são apresentados a composição centesimal e o valor calórico das amostras mensais de surimi, produzidas industrialmente durante o período de um ano. Os teores de umidade variaram entre 79,58 e 88,70 g/100 g com valor médio de 84,31 $\pm 3,36 \mathrm{~g} / 100 \mathrm{~g}$. De acordo com a literatura, essa variação é decorrente da eficiência do processo de centrifugação, mas pode ser influenciada também pela sazonalidade das espécies utilizadas. PARK \& LANIER [33] reportaram a variação na composição química do Alaska pollack ao longo do ano, decorrente dos efeitos sazonais. Os teores de umidade oscilaram entre 80 e 84,5 g/100 g no período de abril a outubro. Os autores ainda afirmaram que, neste período, o peixe apresentava $\mathrm{pH}$ do músculo elevado, retendo mais água e resultando em surimi de qualidade inferior.

A qualidade do surimi produzido no Japão, (espécie Alaska pollack), é avaliada pelo conteúdo de água e pela flexibilidade do gel. É diferenciado em quatro categorias; no que se refere ao teor de umidade: $\mathrm{S}$ (super classe), umidade entre 76,1 e 79,0 g/100 g; A (primeira classe), entre 79,1 e 80,0 g/100 g; B (segunda classe), entre 80,1 e $81,5 \mathrm{~g} / 100 \mathrm{~g} \mathrm{e} \mathrm{C}$ (fora de especificação), quando a umidade for superior a 81,5 g/100 g (SUZUKI [39]). Embora no valor de $75 \mathrm{~g}$ de umidade/100 g o peixe seja apontado como sendo mais propício para a manutenção das propriedades funcionais do surimi (VENUGOPAL \& SHAHIDI [43]), a indústria tem dificuldade em atender a este padrão de qualidade (MANSFIELD [27]).

Os teores protéicos variaram significativamente, entre 9,9 e 18,0 g/100 g, em base úmida, ou entre 83,5 e 90,7 g/100 g, em base seca. Estas diferenças podem ser atribuídas, ao menos parcialmente, à variação de umidade que, por sua vez decorre das diversas variáveis do processo. Essas variáveis incluem o número de ciclos de lavagem que é aplicado para atingir o padrão de cor desejado, a pressão exercida na remoção da água, entre outras. SPENCER \& TUNG [38] reportaram que o número de ciclos de lavagens e a força de compressão exercem efeito importante na redução do conteúdo de proteínas. Estes autores observaram um decréscimo de 12 a 17\% no conteúdo protéico quando comparado ao conteúdo protéico do minced fish. A água solubiliza proteínas sarcoplasmáticas e enzimas que não contribuem para a formação de gel e estas são removidas durante os ciclos de lavagem (HANG-CHING \& LEINOT [14], VENUGOPAL \& SHAHIDI [43]).

TABELA 1 - Composição centesimal e valor calórico do surimi, durante o período de um ano (junho/97 a maio/98)

\begin{tabular}{|c|c|c|c|c|c|c|}
\hline Mês & Umidade $\mathrm{g} / 100 \mathrm{~g}$ & Proteína $\mathrm{g} / 100 \mathrm{~g}$ & Proteína $\mathrm{g} / 100 \mathrm{~g}$ base seca & Lipídios g/100 g & Cinzas $\mathrm{g} / 100 \mathrm{~g}$ & Calorias kcal $/ 100 \mathrm{~g}$ \\
\hline Jun/97 & $88,70 \pm 0,65$ & $9,93 \pm 0,37$ & 87,87 & $0,39 \pm 0,17$ & 0,30 & 43 \\
\hline $\mathrm{Jul} / 97$ & $87,89 \pm 0,42$ & $10,80 \pm 0,39$ & 89,18 & $0,34 \pm 0,15$ & 0,32 & 46 \\
\hline Ago/97 & $87,19 \pm 0,34$ & $11,14 \pm 0,27$ & 86,96 & $0,34 \pm 0,28$ & 0,28 & 48 \\
\hline Set/97 & $87,80 \pm 0,43$ & $10,70 \pm 0,69$ & 87,70 & $0,30 \pm 0,24$ & 0,33 & 46 \\
\hline Out/97 & $83,34 \pm 0,93$ & $13,94 \pm 0,11$ & 83,67 & $0,37 \pm 0,19$ & 0,58 & 59 \\
\hline Nov/97 & $86,93 \pm 0,44$ & $11,67 \pm 0,36$ & 89,29 & $0,16 \pm 0,14$ & 0,30 & 48 \\
\hline Dez/97 & $84,86 \pm 0,94$ & $13,73 \pm 0,39$ & 90,69 & $0,12 \pm 0,49$ & 0,54 & 56 \\
\hline Jan/98 & $80,07 \pm 0,12$ & $18,00 \pm 0,64$ & 90,32 & $0,15 \pm 0,40$ & 0,57 & 73 \\
\hline Fev/98 & $83,01 \pm 0,88$ & $14,82 \pm 0,98$ & 87,23 & $0,38 \pm 0,18$ & 0,32 & 63 \\
\hline Mar/98 & $82,21 \pm 0,77$ & $15,28 \pm 0,66$ & 85,90 & $0,44 \pm 0,47$ & 0,50 & 65 \\
\hline Abr/98 & $79,58 \pm 1,27$ & $17,21 \pm 0,26$ & 84,28 & $0,46 \pm 0,26$ & 0,51 & 73 \\
\hline Mai/98 & $80,15 \pm 0,19$ & $16,57 \pm 0,34$ & 83,48 & $0,61 \pm 0,10$ & 0,51 & 72 \\
\hline Média & $84,31 \pm 3,36$ & $13,65 \pm 2,78$ & 87,21 & $0,33 \pm 0,14$ & 0,37 & 58 \\
\hline
\end{tabular}

Os resultados são médias e desvio padrão de análises em triplicata 
O surimi produzido com a espécie Alaska pollack, estudada pela Alaskan Fisheries Development Foundation, apresentou uma variação sazonal nos teores protéicos de 14 a $19 \%$, com os maiores valores nos meses de novembro $(19,0 \%)$ e maio $(16,5 \%)$ e menores no mês de abril (14-15,0\%), sendo esses valores, provavelmente, reflexo da sazonalidade e do processamento (PARK \& MORRISSEY [32], PARK \& LANIER [33]).

O conteúdo de lipídios foi reduzido, mas foi observada uma variação entre $0,12-0,61 \mathrm{~g} / 100 \mathrm{~g}$, durante os 12 meses, com valores mínimos em novembro/97 até janeiro/98 (média de 0,14\%). A flutuação observada no período de outubro a fevereiro coincide com o período de desova do Paralonchurus brasiliensis, peixe que está presente em maior proporção no surimi estudado. Durante este período de maior atividade do peixe, ocorre significativa mobilização das reservas lipídicas (BURT \& HARDY [6], KOZLOVA [20], LINEHAN et al. [26], MÉNDEZ \& GONZÁLEZ [28]).

A Figura 1 ilustra a variação no conteúdo de proteínas e lipídios durante o período de um ano.

Os teores de minerais oscilaram entre 0,28 e 0,57 g/100 g, com um valor médio de $0,37 \%$. A solubilização de minerais durante as etapas de lavagem do surimi é a causa dos baixos teores verificados.

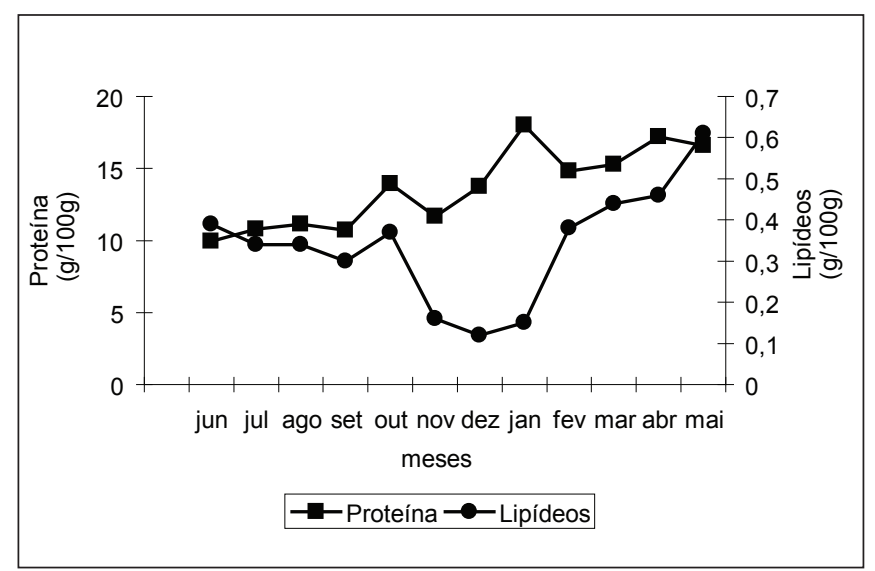

FIGURA 1 - Variação nos teores de proteína e lipídios no surimi durante o período de um ano

O surimi apresentou conteúdo calórico médio de $58 \mathrm{kcal} / 100 \mathrm{~g}$, constituindo-se em produto de baixo valor calórico. SHAHIDI \& SYNOWIECKI [36] observaram valores calóricos similares em estudos com músculo de pescado lavado e separado mecanicamente.

\section{2 - Composição em aminoácidos}

A composição em aminoácidos das amostras de surimi encontra-se na Tabela 2.

TABELA 2 - Composição em aminoácidos de amostras de surimi, no período de um ano (g/100 g de proteína)

\begin{tabular}{|c|c|c|c|c|c|c|c|c|c|c|c|c|c|c|}
\hline Aminoácidos & JUN & JUL & AGO & SET & OUT & NOV & DEZ & JAN & FEV & MAR & ABR & MAI & Média $\pm d p$ & CV (\%) \\
\hline Ácido Aspártico & $12,34^{\mathrm{a}}$ & 10,12 & 10,29 & 10,21 & 10,35 & 10,2 & 10,16 & 9,95 & 10,6 & 10,53 & 10,44 & 10,36 & $10,46 \pm 0,62$ & 5,93 \\
\hline Treonina & $4,05^{\mathrm{a}}$ & 4,54 & 4,74 & 4,70 & 4,69 & 4,71 & 4,68 & 4,51 & 4,78 & 4,71 & 4,56 & 4,57 & $4,60 \pm 0,19$ & 4,13 \\
\hline Serina & $3,48^{a}$ & 3,90 & 4,15 & 4,09 & 4,18 & 4,07 & 4,17 & 4,01 & 4,08 & 4,06 & 4,27 & 3,84 & $4,03 \pm 0,21$ & 5,21 \\
\hline Ácido Glutâmico & 17,31 & 17,68 & 17,93 & 17,9 & 18,15 & 17,83 & 17,77 & 17,85 & 18,1 & 18,05 & 17,73 & 17,46 & $17,81 \pm 0,25$ & 1,4 \\
\hline Prolina & 3,36 & 3,43 & 3,38 & 3,44 & 3,29 & 3,32 & 3,46 & 3,27 & 3,38 & 3,40 & 3,78 & 3,85 & $3,45 \pm 0,18$ & 5,22 \\
\hline Glicina & 3,66 & 4,05 & 4,05 & 3,97 & 3,90 & 3,83 & 4,00 & 3,72 & 4,08 & 4,12 & 3,60 & 3,65 & $3,89 \pm 0,19$ & 4,88 \\
\hline Alanina & 6,13 & 6,14 & 6,14 & 6,11 & 6,11 & 6,09 & 6,04 & 5,90 & 6,08 & 6,10 & 5,88 & 5,84 & $6,05 \pm 0,11$ & 1,82 \\
\hline Cisteína & 0,81 & 0,85 & 0,89 & 0,83 & 0,70 & 0,83 & 0,87 & 1,00 & 0,65 & 0,68 & 0,96 & 1,00 & $0,84 \pm 0,11$ & 13,1 \\
\hline Valina & $5,42^{\mathrm{a}}$ & 4,86 & 4,97 & 4,94 & 4,94 & 4,97 & 5,06 & 5,07 & 4,92 & 4,95 & 4,97 & 5,03 & $5,01 \pm 0,14$ & 2,79 \\
\hline Metionina & $2,93^{a}$ & 3,37 & 3,33 & 3,29 & 3,24 & 3,22 & 3,32 & 3,45 & 3,23 & 3,28 & 3,29 & 3,45 & $3,28 \pm 0,13$ & 3,96 \\
\hline Isoleucina & $5,48^{a}$ & 4,56 & 4,50 & 4,42 & 4,55 & 4,52 & 4,73 & 4,64 & 4,74 & 4,73 & 4,48 & 4,48 & $4,65 \pm 0,28$ & 6,02 \\
\hline Leucina & 8,69 & 8,42 & 8,49 & 8,46 & 8,49 & 8,46 & 8,61 & 8,53 & 8,6 & 8,58 & 8,73 & 8,68 & $8,56 \pm 0,10$ & 1,17 \\
\hline Tirosina & 3,29 & 3,52 & 3,64 & 3,56 & 3,50 & 3,56 & 3,84 & 3,87 & 3,31 & 3,34 & 3,29 & 3,41 & $3,51 \pm 0,20$ & 5,7 \\
\hline Fenilalanina & $4,60^{a}$ & 3,78 & 3,94 & 3,89 & 3,91 & 3,91 & 4,04 & 4,11 & 3,82 & 3,83 & 3,79 & 3,62 & $3,94 \pm 0,24$ & 6,09 \\
\hline Histidina & 2,61 & 3,20 & 3,05 & 3,09 & 2,95 & 2,42 & 2,98 & 2,91 & 2,68 & 2,73 & 3,07 & 3,40 & $2,92 \pm 0,27$ & 9,25 \\
\hline Lisina & 10,61 & 10,19 & 10,05 & 9,9 & 9,92 & 9,69 & 9,97 & 9,95 & 10,2 & 10,2 & 10,13 & 10,12 & $10,08 \pm 0,23$ & 2,28 \\
\hline Arginina & 5,50 & 7,38 & 6,46 & 7,18 & 7,13 & 8,36 & 6,30 & 7,27 & 6,74 & 6,73 & 6,83 & 7,12 & $6,92 \pm 0,69$ & 9,97 \\
\hline Total & 100,27 & 99,99 & 100 & 99,98 & 100 & 99,99 & 100,00 & 100,01 & 100,00 & 100,02 & 99,80 & 99,88 & $99,99 \pm 0,11$ & - \\
\hline
\end{tabular}

(a) Indica diferença significativa $(\mathrm{p}<0,05)$ em relação às demais amostras

$\mathrm{CV}=$ coeficiente de variação 
Não houve diferença estatística entre os teores de aminoácidos das amostras, com exceção à de junho/97, que apresentou teores diferenciados em relação ao ácido aspártico, treonina, serina, valina, metionina, isoleucina e fenilalanina (Tabela 2). Uma hipótese para explicar essa diferença foi o emprego de diferentes proporções das duas espécies de peixe na produção do surimi.

Avaliado quimicamente, o surimi caracterizou-se como fonte protéica de elevado valor biológico, levando em conta o perfil de seus aminoácidos essenciais, como era a expectativa, comparável a outras fontes protéicas de origem animal e vegetal. É capaz de atender às recomendações nutricionais para adultos e para crianças na faixa etária de 3-8 anos (FAO/WHO/UNU [11]), e até para crianças com idade entre 2 a 5 anos que apresentam uma maior necessidade de aminoácidos essenciais (FAO/WHO/UNU [10]) (Tabela 3). Ressalva é feita ao triptofano que não foi quantificado neste estudo, mas cujo conteúdo não deve diferir do pescado original que não é deficiente neste aminoácido.

\section{3 - Teores de mercúrio total}

O mercúrio total oscilou entre 0,23-0,40 mgHg/kg ao longo do ano (Tabela 4), estando abaixo do limite aceito de $0,5 \mathrm{mg} / \mathrm{kg}$ previsto em legislação brasileira para pescado não-predador (BRASIL [5]). É oportuna a quantificação do mercúrio em surimi, pelo fato de o produto ser um concentrado protéico. Via de regra o mercúrio liga-se à cisteína e a contaminação de alimentos com mercúrio constitui-se em aspecto importante na área da saúde pública.

Devido à utilização do mercúrio nas indústrias de cloro-soda, pesticidas, fungicidas, tintas, bem como em atividades de mineração do ouro, este elemento pode ser transportado e distribuído de fontes terrestres para os sistemas hídricos, contaminando oceanos, rios e lagos. As espécies químicas de maior impacto ambiental são o mercúrio elementar, o mercúrio iônico e os organomercuriais, com destaque para o metilmercúrio (KITAHARA et al. [19], YALLOUZ et al. [44, 45]). Este se acumula principalmente no organismo de peixes pelágicos, particularmente nas espécies carnívoras como tubarões e cações, que ocupam o topo da cadeia trófica de alimentos, (LACERDA et al. [22]). CHICOUREL et al. [8], ao analisarem diferentes espécies marinhas nãopredadoras oriundas da pesca industrial, encontraram de 0,026 a 0,132 mgHg/kg. Estes resultados são muito inferiores aos da Tabela 4 (0,23-0,40 mgHg/kg) e podem ser indicativos de enriquecimento do metal no surimi, provocado pelo processamento.

No Brasil, a contaminação mercurial dos rios e lagos, decorrente das atividades garimpeiras de ouro nas regiões do Pantanal mato-grossense e na região Amazônica, com conseqüente contaminação de peixes e humanos,

TABELA 4 - Teores de mercúrio total em surimi durante os meses de agosto de 997 a março de 1998

\begin{tabular}{lc}
\hline Mês & $\begin{array}{c}\text { Mercúrio }(\mathrm{mg} / \mathbf{k g}) \\
\text { Base úmida }\end{array}$ \\
\hline Agosto & 0,23 \\
Outubro & 0,30 \\
Novembro & 0,26 \\
Dezembro & 0,31 \\
Janeiro & 0,30 \\
Fevereiro & 0,40 \\
Março & 0,38 \\
\hline
\end{tabular}

TABELA 3 - Composição em aminoácidos do surimi, de outras fontes protéicas* e os requerimentos da FAO

\begin{tabular}{|c|c|c|c|c|c|c|c|c|}
\hline $\begin{array}{l}\text { Aminoácidos (g/100 } \\
\text { g de proteína) }\end{array}$ & Surimi & $\begin{array}{l}\text { Conc. protéico } \\
\text { de peixe }\end{array}$ & Carne & $\begin{array}{l}\text { Conc. soro } \\
\text { de leite }\end{array}$ & Caseína & Conc. de soja & $\mathrm{FAO}^{\mathrm{a}} 2-5$ anos & $\mathrm{FAO}^{\mathrm{b}} 3-8$ anos \\
\hline Ác. Aspártico & 10,46 & 10,75 & 8,99 & 12,3 & 7,13 & 12,11 & & \\
\hline Treonina & 4,60 & 5,13 & 4,59 & 6,18 & 4,66 & 4,44 & 3,4 & 0,9 \\
\hline Serina & 4,03 & 5,43 & 4,03 & 4,76 & 6,03 & 5,95 & & \\
\hline Ác. Glutâmico & 17,81 & 16,05 & 15,28 & 20,41 & 22,04 & 20,62 & & \\
\hline Prolina & 3,45 & 4,70 & 3,78 & 5,18 & 11,57 & 5,49 & & \\
\hline Glicina & 3,89 & 7,53 & 4,86 & 1,92 & 1,97 & 4,48 & & \\
\hline Alanina & 6,05 & 6,90 & 5,84 & 6,11 & 3,07 & 4,52 & & \\
\hline Cisteína & 0,84 & 1,40 & 1,28 & 2,51 & 2,51 & 1,52 & & \\
\hline Valina & 5,01 & 5,68 & 5,01 & 6,42 & 6,74 & 5,59 & 3,5 & 1,3 \\
\hline Metionina & 3,28 & 3,77 & 2,70 & 2,64 & 2,79 & 1,38 & $2,5^{c}$ & $1,7^{c}$ \\
\hline Isoleucina & 4,65 & 5,08 & 4,82 & 6,92 & 5,41 & 5,28 & 2,8 & 1,3 \\
\hline Leucina & 8,56 & 8,61 & 8,11 & 14,01 & 9,51 & 8,21 & 6,6 & 1,9 \\
\hline Tirosina & 3,51 & 4,22 & 3,60 & 3,50 & 5,82 & 3,78 & & \\
\hline Fenilalanina & 3,94 & 4,65 & 4,40 & 3,82 & 5,24 & 5,42 & $6,3^{d}$ & $1,9^{d}$ \\
\hline Triptofano & n.d. & 1,20 & 1,54 & 2,60 & 1,68 & 1,50 & 1,1 & 0,5 \\
\hline Histidina & 2,92 & 2,68 & 3,41 & 2,05 & 2,92 & 2,78 & 1,9 & 1,6 \\
\hline Lisina & 10,08 & 8,45 & 8,90 & 11,20 & 8,12 & 6,76 & 5,8 & 1,6 \\
\hline Arginina & 6,92 & 6,86 & 6,32 & 3,01 & 3,75 & 8,05 & & \\
\hline
\end{tabular}

*Dados de outras fontes protéicas adaptadas de ADLER-NISSEN [1]

aRecomendações de aminoácidos essenciais, FAO/WHO/UNU [10], para crianças de 2-5 anos

${ }^{\circ}$ Recomendações de aminoácidos essenciais, FAO/WHO/UNU [11], para crianças de 3-8 anos

'Metionina + cisteína

${ }^{\mathrm{d}}$ Fenilalanina + tirosina 
tem sido reportada em vários estudos, demonstrando que o monitoramento constante se faz necessário não somente nessas regiões, mas também em toda a costa litorânea, devido a migração das espécies (KITAHARA et al. [19], LACERDA \& PFEIFFER [21], PINHEIRO et al. [34], YOKOO [46]).

Entre os fatores que influenciam o grau de exposição humana aos riscos de contaminação por mercúrio através do pescado, merecem destaque: a freqüência de ingestão, preferência de consumo, tamanho e nível trófico das espécies (BRABO et al. [4]).

Mundialmente, foram estabelecidos limites que variam de 0,4 a 1,0 mgHg/kg de pescado. No Japão, o limite é 0,4 mg, na Itália é 0,7 mg e nos Estados Unidos, o limite adotado é $1,0 \mathrm{mgHg} / \mathrm{kg}$, apenas para citar alguns exemplos (KITAHARA et al. [19], MORALES-AIZPURÚA et al. [30]).

No Brasil, a legislação estabelece os limites de tolerância para peixes e produtos da pesca de 0,5 e 1,0 mgHg/kg para não-predadores e predadores, respectivamente. Para qualquer outro tipo de alimento, o limite é $0,1 \mathrm{mgHg} / \mathrm{Kg}$ (Portaria no 685, Brasil 1998 [5]).

Observa-se, porém, que a legislação brasileira, apesar de discernir entre tipos de peixe, não contempla o surimi e outros produtos dele derivados, produzidos exclusivamente à base de pescado, como é o caso dos nuggets, hambúrgueres, kani kama, etc. Portanto, seria prudente e aconselhável incluir esses produtos na categoria de "outras espécies de peixes", admitindo uma concentração de até 0,5 ppm (0,5 mgHg/kg).

\section{4 - CONCLUSÕES}

Surimi produzido industrialmente a partir de duas espécies de peixes marinhos e analisado mensalmente durante um ano permitiu caracterizar este produto nutricionalmente e com relação à eventual contaminação por mercúrio. O produto evidenciou uma concentração protéica variando entre 10 e $18 \%$, com excelente perfil de aminoácidos atendendo às recomendações nutricionais tanto para adultos como crianças. As diferenças encontradas nos teores protéicos sugerem a influência de variáveis do processo que é aplicado pela empresa para atingir o padrão de cor desejado. Os teores de lipídeos foram reduzidos e os de carboidratos insignificantes e os níveis de mercúrio encontravam-se dentro dos limites estabelecidos pela legislação.

O surimi desponta como matéria prima para a produção de inúmeros alimentos análogos ao pescado de excelente qualidade nutricional, embora estudos complementares sejam necessários para o estabelecimento de um padrão de identidade e de qualidade de surimi produzido no Brasil e para orientar os fabricantes na obtenção e manutenção da qualidade de seus produtos.

\section{5 - REFERÊNCIAS BIBLIOGRÁFICAS}

[1] ADLER-NISSEN, J. Enzymic Hydrolysis of Food Proteins. Barking, England: Elsevier Applied Science
Publishers Ltd, 1986.

[2] AOAC Official Methods of Analysis, $16^{\text {th }}$ ed. Association of Official Analytical Chemists, Arlington, VA, 1995.

[3] ARECHE, N.T. Procesiamento de pastas y carnes desintegradas de pescado. Inst. Tec. Pesq., 1989.

[4] BRABO, E.S.; OLIVEIRA, E.; JESUS, I.M.; MASCARENHAS, A.F.; FAIAL, K.F. Níveis de mercúrio em peixes consumidos pela comunidade indígena de Sai Cinza na Reserva Munduruku, Município de Jacareacanga, Estado do Pará, Brasil. Cad. Saúde Pública, v. 15, n. 2, p. 325-331, 1999.

[5] BRASIL. Leis, decretos, etc. Portaria n ${ }^{\circ}$ 685/98. Diário Oficial, Brasília, séc 1, pt. 1, p. 1415-1437, 24 set. 1998.

[6] BURT, J.R.; HARDY, R. Composition and deterioration of pelagic fish. In: BURT, J.R.; HARDY, R. \& WHITTLE, K.J. Pelagic Fish. Oxford: Fishing News Books, 1992.

[7] CARLBERG, J.M. \& VAN OLST, J.C. U.S. Aquaculture: Current status and future directions. Aquaculture Magazine. v. 27, n. 4, Jul/Aug, 2001.

[8] CHICOUREL, E.L. et al. Mercúrio em pescado comercializado em São Paulo-SP. Ciênc. Tecnol. Aliment., v. 15, n. 2, p. 144-149, 1995.

[9] EEUU. Exportaciones de products pesqueros a la UE aumentaron un $23 \%$ en el 2004. Noticias commerciales. Disponível em: www.infopesca.org. Acesso em 18/04/2005.

[10] FAO/WHO/UNU. Energy and Protein Requirements. Report of a Joint FAO/WHO/UNU Expert Consultation. World Health Organization Technical Report Series no. 724, Geneva, 1985.

[11] FAO/WHO/UNU. Protein Quality Evaluation. Report of a Joint FAO/WHO/UNU Expert Consultation. World Health Organisation, 1991.

[12] FOLCH, J.; LEES, M. \& SLOANE STANLEY, G. H. A simple method for the isolation and purification of total lipids from animal tissues. J. Biol. Chem., v. 226, p. 406-509, 1957.

[13] HALL, G. M. \& AHMAD, N. H. Surimi and fish-mince products. In: HALL, G. M. \& AHMAD, N. H. Fish Processing Technology, 2-6 Boundary Row, London SEI 8HN. UK, Chapmann \& Hall, 1997, p. 75-92.

[14] HANG-CHING, L. \& LEINOT, A. Surimi composition and technology: present status and nutritional considerations. Internat J Food Sci Nutr, v. 44, Suppl. 1, p. S55S63, 1993.

[15] IBAMA/IBGE. Estatística da Pesca. CEPENG, Tamandaré, PE, 1995. Apud. In: VASCONCELLOS, M. \& GASALLA, M.A. Fisheries catches and the carrying capacity of marine ecosystems in southern Brazil. Fisheries Research, v. 50, p. 279-295, 2001.

[16] ISHIKAWA, Y. World surimi market outlook, Infofish Int., v. 1, p. 16-21, 1996.

[17] JESUS, R.S. de; LESSI, E. \& TENUTA-FILHO, A. Estabilidade química e microbiológica de "minced fish" de peixes amazônicos durante o congelamento. Ciênc. Tecnol. Aliment., v. 21, n. 2, p. 144-148, 2001.

[18] JOHNSTON, W. A. Surimi-an introduction. Eur. Food Drink Rev., v. 4, p. 21-24, 1989. 
[19] KITAHARA, S.E. et al., Mercúrio total em pescado de água-doce. Ciênc. Tecnol. Aliment.,v. 20 n. 2, p. 267-273, 2000.

[20] KOZLOVA, T. A. Seasonal cycles in total chemical composition of two Lake baikal benthic-pelagic sculpins (Cottocomephorus cottoidei). J. Fish Biology, v. 50, p. 734-743, 1997.

[21] LACERDA, L.D. \& PFEIFFER, W.C. Mercury contamination in the Madeira River Amazon- $\mathrm{Hg}$ inputs to the environment. Biotropica, v. 21, n. 1, p. 91-93, 1989.

[22] LACERDA, L.D.; PARAQUETTI, H.H.M.; MARINS, R.V.; REZENDE, C.E.; ZALMON, I.R.; GOMES, M.P; FARIAS, V. Mercury content in shark species from the south-eastern Brazilian coast. Rev. Brasil. Biol., v. 60, n. 4, p. 571-576, 2000.

[23] LEE, C. M. Surimi process technology. Food Technol., v. 38, p. 69-80, 1984.

[24] LEE, C. M. Surimi Process Technology. In: Engineered Seafood Including Surimi, Washington, DC: Ed. Roy E. Martin \& Robert L. Collette, National Fisheries Institute, 1990, p 710-721.

[25] LEE, C. M. Surimi processing from lean fish. In SHAHIDI, F. \& BOTTA J. R., Seafoods: Chemistry, Processing Technology and Quality, Bishopbriggs, Glasgow G64 2 NZ, UK, ed. Chapman \& Hall, 1994, cap. 14, p. 263-287.

[26] LINEHAN, L.G.; O'CONNOR, T.P. \& BURNELL, G. Seasonal variation in the chemical composition and fatty acid profile of Pacific oysters (Crassostrea gigas) Food Chem., v. 64, p. 211-214, 1999.

[27] MANSFIELD, B. Fish, factory trawlers, and imitation crab: the nature of quality in the seafood industry. Department of Geography, Ohio State University. Disponível em: http://www2.ucsc.edu/globalinterns/ cpapers/mansfieldpap.pdf, 20 p., 2001. Acesso em $13 / 04 / 2005$

[28] MÉNDEZ, E. \& GONZÁLEZ, R.M. Seasonal changes in the chemical and lipid composition of fillets of the Southwest Atlantic hake (Merluccius hubbsi). Food Chem., v. 59, n. 2, p. 213-17, 1997.

[29] MOORE, S. On the determination of cystine as cysteic acid. J. Biol. Chem., Bethesda, v. 238, n. 1, p. 235237, 1963.

[30] MORALES-AIZPURÚA, I.C.; TENUTA-FILHO, A.; SAKUMA, A.M.; ZENEBON, O. Mercúrio total em cação comercializado em São Paulo-SP, Brasil. Ciênc. Tecnol. Aliment., v. 19, n. 3, p. 429-432, 1999.

[31] NETER, J.; WASSERMAN, K. \& KUTNER, M. H. 1985. Applied Linear Statistical Models: Regression, Analysis of Variance and Experimental Designs ( $2^{\text {nd }}$ ed.). Richard D. Irwin, Homewood.

[32] PARK, J.W. \& MORRISSEY, M.T. Manufacturing of surimi from light muscle fish. In.: PARK, J. W., Surimi and Surimi Seafood. New York: Marcel Dekker, Inc., 2000, p. 23-37.

[33] PARK, J.W. \& LANIER, T.C. Processing of surimi and surimi seafoods. In.: MARTIN, R.E.; CARTER, E.P.; FLICK Jr.; G.J. and DAVIS, L.M., Marine \& Freshwater Products Handbook, Lancaster, Pennsylvania: Technomic Publishing Company, Inc., 2000, p. 417-443.
[34] PINHEIRO, M.C.N.; NAKANISHI, J.; OIKAWA, T.; GUIMARÃES, G.; QUARESMA, M.; CARDOSO, B.; AMORAS, W.W.; HARADA, M.; MAGNO, C.; VIEIRA, J.L.F.; XAVIER, M.B.; BACELAR, D.R. Exposição humana ao metilmercúrio em comunidades ribeirinhas da região do Tapajós, Pará, Brasil. Rev. Soc. Bras. Med. Trop., v. 33, n. 3, p. 265-269, 2000.

[35] RUSTAD, T. Utilization of marine by-products. EJEAFChe, v. 2, n. 4, p. 1-9, 2003.

[36] SHAHIDI, F. \& SYNOWIECKI, J. Nutrient composition of mechanically separated and surimi-like seal meat. Food Chem., v. 47, p. 41-46, 1993.

[37] SPACKMAN, D.H.; STEIN, W.H. \& MOORE, S. Automatic recording apparatus for use in the chromatography of amino acids. Anal. Chem., v. 30, p. 1190-1206, 1958.

[38] SPENCER, K.E. \& TUNG, M. A. Surimi processing from fatty fish. In SHAHIDI, F. \& BOTTA J. R., Seafoods: Chemistry, Processing Technology and Quality, Bishopbriggs, Glasgow G64 2 NZ, UK, ed. Chapman \& Hall, 1994, cap.15, p. 288-319.

[39] SUZUKI, T. Fish and Krill Protein: Processing Technology. Applied Science Publishers, Barking, Essex, 1981.

[40] TENUTA-FILHO, A \& JESUS, R.S. Aspectos da utilização de carne mecanicamente separada de pescado como matéria-prima industrial. Bol. sbCTA, v. 37, n. 2, p. 59-64, 2003

[41] United States of America. Department of Commerce. Current Fisheries Statistics n. 2004-2. Imports and exports of fishery products annual summary, 2004. Disponível em: http://www.nmfs.nava.gov/st1/ trade/documents/trade2004.pdf no site NOA FISHERIES: Office of Science \& Technology. Acesso em 18/04/2005.

[42] VASCONCELlOS, M. \& GASALlA, M.A. Fisheries catches and the carrying capacity of marine ecosystems in southern Brazil. Fisheries Res., v. 50, p. 279-295, 2001.

[43] VENUGOPAL, V. \& SHAHIDI, F. Value-added products from underutilized fish species. Crit Rev Food Sci Nutr., v. 35, n. 5, p. 431-453, 1995.

[44] YALLOUZ, A.; CAMPOS, R.C. \& LOUZADA, A. Níveis de mercúrio em atum sólido enlatado comercializado na cidade do Rio de Janeiro. Ciênc. Tecnol. Aliment., v. 21, n. 1, p. 1-4, 2001.

[45] YALLOUZ, A.V.; CALIXTO, T.; HACON, S. Semiquantitative mercury determination in fish: a tool for poisoning prevention. An. Acad. Bras. Ciênc., v. 74, n. 1, p. 187-191, 2002.

[46]YOKOO, E.M. Avaliação da exposição ao metilmercúrio na população ribeirinha da baixada cuiabana, no Pantanal mato-grossense-Brasil. Rio de Janeiro, 2001. 117 p. Tese de Doutorado, Universidade do Estado do Rio de Janeiro, Instituto de Medicina Social.

\section{6 - AGRADECIMENTOS}

Os autores agradecem a CAPES pela bolsa de estudos, ao Dr. Alfredo Tenuta-Filho pelas sugestões, ao Instituto Adolfo Lutz, pela análise de mercúrio e à Empresa Takaki Cia Ltda pela doação do surimi. 